\title{
Análise da resposta cartesiana acerca de como pode a alma mover o corpo na Correspondência com Elisabeth
}

Analysis of the cartesian response on how the soul can move the body in Correspondence with Elisabeth 
RESUMO: Trata-se de abordar uma das questões com mais desdobramentos que já foram dirigidas à filosofia cartesiana, a saber, como pode a alma mover o corpo, na carta endereçada a Elisabeth de 2I de maio de I643. Isso exige uma reflexão sobre como Descartes estabeleceu com tanta segurança a ordem das razões nas Meditações, e como colocou a união substancial dentro dela, pois na Correspondência afirmou-se que essa união não pode ser entendida pela razão.

PALAVRAS-CHAVE: união substancial; Correspondência; substância pensante; substância extensa.

ABSTRACT: Addresses one of the most unfolding questions that has already been addressed to Cartesian philosophy, how can the soul move the body, in the letter addressed to Elisabeth of May 2I, I643. This calls for a reflection on how Descartes so safely established the order of reasons in Meditations, and how he placed the substantial union within it, because in Correspondence it was stated that this union can not be understood by reason.

KEYWORDS: substantial union; Correspondence; thinking substance; extensive substance. 


\section{INTRODUÇÃO}

A carta endereçada a Elisabeth de 2i de maio de 1643 cuida de uma das questões pouco estudadas mas com longos desdobramentos que já foram dirigidas à filosofia cartesiana, a saber, como pode a alma mover o corpo'. Nessa carta, Descartes busca explicar a maneira pela qual concebe a união da alma com o corpo e como a alma tem a força de movê-lo, pois, apesar de ter explicado como se dá a união em um de seus textos anteriores, as Meditações metafísicas, a leitora Elisabeth encontra dificuldade em entender esse ponto e, como consequência, abre a questão central aqui vista. Isso ocorre principalmente por Elisabeth não ter entendido como a alma, substância completa e inextensa cuja faculdade principal é o pensamento, consegue estar unida ao corpo, e mais, como ela pode implicar movimentos - algo naturalmente extenso e que necessita de contato físico em outra substância completa e totalmente diferente.

O foco é explicar a razão de Descartes ter pedido a Elisabeth que atribuísse extensão à alma². Para mostrar os passos necessários a fim de

\footnotetext{
I “(...) me dire comment l'âme de l'homme peut déterminer les esprits du corps, pour faire les actions volontaires (n'étant qu'une substance pensante)" (DESCARTES, 2005, p.I744).

2 "Mas, visto que Vossa Alteza nota que é mais fácil atribuir matéria e extensão à alma do que atribuir-lhe capacidade de mover um corpo e de ser movida por ele, sem possuir matéria, suplico-lhe que queira livremente atribuir esta matéria e esta extensão à alma; pois isto não é mais do que concebê-la unida ao corpo" (DESCARTES, I973, p. 314).
} 
se entender como a alma tem o poder de mover o corpo, vê-se não só no que foi respondido na Correspondência, mas também em outras obras cartesianas, como As paixões da alma e Meditações, e conclui-se que Descartes responde à questão, mas não da forma como Elisabeth esperava, pois ela contém uma impossibilidade de resposta racional. Partindo disso, torna-se interessante lembrar alguns pontos das cartas de 2i de maio e 28 de junho de 1643 escritas por Descartes a Elisabeth.

\section{CARTA DE 21 DE MAIO DE 1643}

Ao tentar entender a pergunta de Elisabeth, logo no início da carta, Descartes assume que falou pouco nas Meditações de como a alma está unida ao corpo e consequentemente de como pode agir e padecer com ele. Sabe que por ter focado longamente a distinção entre as duas substâncias alma e corpo - por causa de seu projeto metafísico -, abriu espaço para dúvidas como a de Elisabeth surgirem.

(...) pois, havendo duas coisas na alma humana, das quais depende todo conhecimento que podemos ter de sua natureza, uma das quais é que ela pensa e a outra, que, estando unida ao corpo, pode agir e padecer com ele, quase nada disse da última e empenhei-me apenas em aclarar bem a primeira, porque o meu principal intuito era provar a distinção que há entre a alma e o corpo; para o que, somente este podia servir e a outra seria nociva (DESCARTES, 1973, p. 309).

Sobre esse projeto metafísico, vale notar, segundo Gueroult (I99I, p. I8), que o esforço cartesiano se compromete desde o início para o estabelecimento de um sistema total de conhecimentos certos tanto científicos quanto metafísicos, sistema esse fundamentalmente diferente do aristotélico, inteiramente imanente à certeza matemática e envolto em ideias claras e distintas. Esse sistema não é um conjunto de conhecimentos 
enciclopédicos, mas uma unidade fundamental de princípios primeiros donde seguem todos os conhecimentos certos possíveis.

Com isso, vê-se que Descartes não poderia ter mais bem explicado a união nas Meditações, pois esse conhecimento não se dá de forma clara e distinta. Afirma-se que o conhecimento da distinção e aquele da união se referem a conhecimentos diferentes, isto é: o primeiro, à razão, e o segundo, ao sentimento. Para alcançar o primeiro, deve-se fechar os olhos e as orelhas, ou seja, desviar-se dos sentidos; mas, para alcançar o segundo, deve-se desviar do entendimento puro, das ideias claras e distintas e, em particular, das razões que provam a distinção das substâncias, para abandonar-se inteiramente à experiência do sentimento (GUEROULT, I99I, p. 9).

Entretanto, suscitado pela pergunta de Elisabeth e a fim de responder como se dá a união substancial, o autor se dedica na carta de 2i de maio a explicar melhor esse assunto. Para isso, insere o conceito de noção primitiva, que são aquelas noções que só podem ser entendidas por si mesmas por serem as mais fundamentais e simples. E continua, explicando como isso interfere no conhecimento que temos da substância extensa, da substância pensante e da união substancial.

Porém a forte presença da dificuldade está quanto ao conjunto alma e corpo, pois temos a noção de união - que não pode ser confundida como uma adição da noção de pensamento com a noção de extensão -, da qual depende a força de que dispõe a alma para mover o corpo e o corpo para atuar sobre a alma, causando os sentimentos e as paixões (DESCARTES, I973, p. 310).

Ao final da carta, Descartes escreve:

(...) confundimos até agora a noção da força com que a alma atua no corpo e aquela com que um corpo atua em outro; e que atribuímos ambas não à alma, pois não a conhecíamos ainda, porém às 
diversas qualidades dos corpos, como a gravidade, o calor e as outras, que imaginamos serem reais, isto é, possuírem uma existência distinta da do corpo e, por conseguinte, serem substâncias, embora as denominássemos qualidades (1973, p. 3ro).

Por esse comentário, podemos ver que quando nos servimos da distinção para explicar como a alma atua no corpo somos levados a estudar as qualidades das duas substâncias separadamente e caímos, então, no erro de ver a interação alma-corpo dada da mesma forma que uma interação corpo-corpo. Porém, como dito nas Meditações, a alma não é um piloto que governa o corpo, mas está unida a ele de tal forma, que não se pode separá-la em sua interação.

Esse texto (carta a Elisabeth de 2i maio de i643) indica que a concepção de união da alma com o corpo não é desenvolvida suficientemente. Isto irá requerer todo um livro: As paixões da alma. Porém, não significa que as Meditações devam ser deixadas de lado, pois é lá que essa evidência se apresenta com a maior força e onde está ligada à ordem das razões.

\section{CARTA DE 28 DE JUNHO DE 1643}

Elisabeth escreve novamente a Descartes com a mesma questão. Note-se que a dúvida segue não porque Elisabeth não entendeu que se devia analisar a união substancial por meio da noção primitiva de união, pois isso já fora dito a ela na carta anterior, mas por não compreender como movimento e força - características exclusivamente materiais - poderiam ser causadas por uma substância imaterial. Ou seja, a dificuldade está em entender como um corpo pode ser impelido ${ }^{3}$ por algo imaterial, ou como a

3 A partir da nota 7 da edição usada nesse trabalho (1973) à carta de 28 de junho de i643, temos: "Elisabeth respondera mais ou menos assim: não entendo por que, ao denunciar a falsidade da noção da gravidade, quereis nos persuadir, quando se trata do corpo humano, de "que um corpo pode ser impelido por algo imaterial"' (DESCARTES, I973, p. 313). 
alma pode causar impacto no corpo através do movimento. Para assimilar isso, aconselha Descartes a Elisabeth que pare de filosofar e volte à vida comum, porque é com a filosofia que conhecemos a distinção real entre a alma e o corpo, o que nos atrapalha na compreensão da união substancial. Sabe-se que a união da alma e do corpo não se conhece pelo entendimento nem pelo entendimento ajudado pela imaginação, e, sobretudo, como só pode haver conhecimento certo pelo entendimento, o conhecimento possível da união deve ser inevitavelmente incerto e confuso. Segundo Teixeira (I990, p. 96), esse conhecimento em Descartes será aquele da vida e das conversações ordinárias, pois conceber a união é "atribuir matéria e extensão à alma", e isto é, sem dúvida, o cúmulo da confusão.

Uma coisa é certa: filosofar sobre a união substancial ou mesmo sobre como pode a alma mover o corpo só traz dificuldades. Aqueles que são habituados a filosofar e que, afastados dos sentidos, se movem na esfera do entendimento puro, não podem conceber a união que contradiz a evidência racional da distinção necessária das duas substâncias, conforme Gueroult (I99I, p. 9). O motivo disso se encontra nas diferenças entre as três noções primitivas e, consequentemente, entre as operações da alma correspondentes, pelo fato de a alma ser concebida clara e distintamente pelo entendimento puro, do corpo ser concebido distintamente pelo entendimento com a ajuda da imaginação, e, por fim, da união ser concebida obscuramente pelo entendimento e imaginação, e ser conhecida claramente pelos sentidos. Pois o erro surge quando se confundem as noções primitivas, ou a união substancial com a separação das substâncias.

Surge a pergunta de se o fato de Descartes deixar que Elisabeth conceba a interação alma-corpo atribuindo extensão à alma não seria um erro dentro de seu sistema, pois a alma é inextensa - o que foi explicado com afinco nas Meditações. Porém vale notar que a extensão que, na carta, se atri- 
bui à alma para entender a união não é a extensão mesma como a concebemos nas Meditações, pois conceber a alma como tendo extensão e matéria é compreendê-la como unida ao corpo. Além disso, não há perigo porque, nas Meditações, já se sabe suficientemente da distinção entre as substâncias para se entender que a alma jamais possuirá a extensão do corpo.

\section{MEDITAÇÕES METAFISICAS}

Inicia-se pela Primeira meditação, na qual Descartes rejeita qualquer falsa opinião ou princípio mal assegurado, isto é, qualquer opinião incerta e duvidosa, para, a partir disso, encontrar algo de seguro nas ciências, pois estava focado na construção de uma "árvore do saber" a partir de uma nova metafísica, a qual esperava estar assentada em princípios claros e distintos.

Para isso, a dúvida cartesiana apresentada nas Meditações ganha papel de destaque ao colocar menos em causa o objeto como tal do que as opiniões relativas a esse mesmo objeto. Em outras palavras, Descartes colocou como incertas as opiniões acerca dos objetos e não os objetos em si, dando lugar a uma nova metafísica. Dizemos "nova metafísica" pois, a partir da primeira certeza estabelecida, a saber, o "eu penso, eu existo", podemos chamá-la de metafísica do sujeito, e, também, Descartes rompe com toda a ciência do provável, a ciência de tipo medieval em que tudo permanece em discussão, segundo Alquie (1969, p. 64).

Como atestado pelo autor, após rever que tudo aquilo que aprendeu, aprendeu como verdadeiro e certo pelos sentidos, e tendo sido várias vezes enganado por conhecimentos desse tipo, resolve afastar qualquer credibilidade nessa possível fonte de conhecimento. Entretanto, pela razão, estabelece que ainda que as coisas mais gerais que são conhecidas pelos sentidos possam ser enganosas, há certas coisas mais simples e universais que são verdadeiras e existentes das quais não se pode duvidar, como 
a figura, o espaço, o tempo e a quantidade. Com essa conclusão, Descartes está seguro de que o caminho da razão, isto é, aquele que se concentra em meditar e conhecer e não em agir, não apresenta perigos, pois nele o juízo não poderá ser dominado pelos maus usos anteriores.

Após haver notado o que cumpre fazer ou evitar para chegar ao conhecimento da verdade, Descartes tenta ver se não é possível conhecer nada de certo no tocante às coisas materiais. Mas, antes de examinar se tais coisas existem fora dele, considera tais ideias na medida em que se encontram em seu pensamento e vê quais são distintas e quais são confusas. Encontra, então, uma infinidade de ideias que não podem ser consideradas um puro nada, e que não são fingidas, pois possuem naturezas verdadeiras conhecidas clara e distintamente (DESCARTES, I973, p. I3I). Com essa certeza, pode agora assegurar que quanto às ideias claras e distintas das coisas corporais há algumas dentre elas que se pode tirar da ideia do próprio pensar, ou melhor, da ideia que tem de si mesmo, como a ideia "de substância, de duração, do número e de outras coisas semelhantes" (DESCARTES, I973, p. II5).

Com a essência do espírito estabelecida e o pensamento livre de maus usos pode-se pesquisar a essência dos corpos, e, para isso, Descartes invoca um argumento que se tornou muito conhecido, a saber, o exemplo do pedaço de cera: a mesma cera permanece após a modificação de suas qualidades sensíveis, pois o que há nela de distinto não é notado por intermédio dos sentidos.

Ora, estávamos dizendo que, com a dúvida nos sentidos instaurada, restou apenas o pensamento como fonte possível de conhecimento certo. Desse próprio pensar, conseguiu-se retirar a essência - e existência - do sujeito, além de ideias "mui certas", como a ideia de extensão. É essa ideia de extensão que permitiu dizer que a cera de antes é a mesma cera de 
após a mudança de cheiro, cor e textura - não é pela imaginação que o asseguramos, mas somente pelo entendimento que a concebemos. Então, estabelecidas a substância pensante (res cogitans) e a substância extensa (res extensa), e sabendo que ambas são concebidas pelo espírito, Descartes dá um passo na cadeia de razões e estabelece na Meditação sexta a união de fato entre a alma e o corpo, mesmo que ao final e de forma rápida.

Atesta-se o fato de ser um desenvolvimento natural dentro do projeto metafísico cartesiano que a união substancial tenha aparecido somente na última Meditação, pois Descartes precisava focar o estabelecimento de um conhecimento certo e seguro por meio da razão, no qual a experiência da união se tornava nociva. Porém na "árvore do saber" o autor não podia deixar as substâncias separadas, pois sair da metafísica e entrar numa nova física requer conhecimentos que envolvam o homem como um sujeito da experiência e não afastado de qualquer sensibilidade.

Pretendendo partir para a física (no tronco de sua árvore), não pôde parar na certeza de que a alma é uma substância inextensa e completamente diferente do corpo. Precisando analisar esse corpo particular, Descartes afirma que tinha alguma razão em acreditar que o corpo que chamava de seu lhe pertencia mais propriamente e mais estreitamente que qualquer outro, pois sentia nele todos seus apetites e todas suas afecções, não podendo ser separado dele. Assim, não podia apresentar nenhuma razão senão que a natureza lhe ensinava estarem essas coisas ligadas à sua alma (DESCARTES, I973, p. I40). E dá um passo além, pois vê que a natureza ensina também, "por esses sentimentos de dor, fome, sede, etc., que não somente estou alojado em meu corpo, como um piloto em seu navio, mas que, além disso, lhe estou conjugado muito estreitamente e de tal modo confundido e misturado, que componho com ele um único todo" (DESCARTES, I973, p. I44). 
Ora, esses sentimentos "nada são exceto maneiras confusas de pensar que provêm e dependem da união e como que da mistura entre o espírito e o corpo". Dessa forma, consegue estabelecer com segurança que seu corpo, "ou, antes, eu mesmo por inteiro, na medida em que sou composto do corpo e da alma, pode receber diversas comodidades ou incomodidades dos outros corpos que o circundam" (DESCARTES, I973, p. I44). Segundo Landim (I992, p. 83), a análise do sentir comprova a estreita ligação da alma com o corpo: as experiências da dor, da sede, da fome, do prazer etc. atestam e exprimem o fato da união. Sobretudo, Descartes atesta a união real e substancial para se contrapor à "concepção angélica do homem”, isto é, a visão de que o homem seria um piloto (alma) que conduziria o seu navio (corpo).

Assim, já há nesse momento pequenas explicações que auxiliam a pensar o problema posto pela Elisabeth. Por exemplo, Descartes assegura que o corpo é divisível e a alma, indivisível, sendo impossível que ela seja pensada como dividida pelo corpo, isto é, tendo partes em diversos lugares. Para resolver isso, Descartes coloca que "o espírito não recebe imediatamente a impressão de todas as partes do corpo, mas somente do cérebro, ou talvez mesmo de uma de suas menores partes, a saber, aquela onde se exerce a faculdade que chamam o senso comum, a qual, todas as vezes que está disposta da mesma maneira, faz o espírito sentir a mesma coisa” (I973, p. I47).

Define-se bem que a alma não precisa ser extensa e que ela pode mover todas as partes do corpo, até aquelas "mais distantes", pois, além de o corpo ser um organismo harmônico no qual todas as partes estão ligadas, a alma não está dividida no corpo, mas está por todo o corpo conjuntamente, isto é, não causa o movimento dos músculos movendo a si, e o corpo não necessita estar grudado fisicamente a ela para ser movido, basta que esteja unido substancialmente. Posto isso, se torna mais fácil a Descartes deixar que Elisabeth atribua extensão à alma para poder lidar com o fato de que 
a reposta à sua pergunta seja dada pela experiência, pois explicou como a alma pode continuar tendo sua essência pensante e estar unida ao corpo.

\section{AS PAIXÕES DA ALMA}

A primeira parte das As paixões da alma trata "das paixões em geral e ocasionalmente de toda a natureza do homem" (DESCARTES, I973, p. 225). Veremos como nela é apresentada a união da alma com o corpo e sua interação, bem como a explicação dos movimentos corporais com base na fisiologia do corpo e mais precisamente da glândula pineal.

Para entendermos melhor como Descartes respondeu a Elisabeth e como aprofundou as questões colocadas na Meditação sexta, destacam-se alguns artigos dessa primeira parte do livro. $\mathrm{O}$ artigo 2 se concentra na união da alma e do corpo segundo a apresentação da ação e da paixão como acontecimentos do mesmo evento e mostra que "não notamos que haja sujeito que atue mais imediatamente contra nossa alma do que o corpo ao qual está unida, e que, por conseguinte, devemos pensar que aquilo que nela é uma paixão é comumente nele uma ação" (DESCARTES, I973, p. 227).

Assim, tem-se que As paixões da alma classificam as maneiras de pensar por meio do par conceitual atividade/passividade, analisando-os sob o prisma da causalidade, segundo Landim (I992, p. 84), pois a ação da alma sobre o corpo é considerada uma maneira de pensar e denominada vontade, enquanto as percepções da alma são consideradas sua passividade. Descartes explica que, na alma, por um lado, há ações (vontades) que "sentimos que vêm diretamente da alma e parecem depender apenas dela” (DESCARTES, I973, p. 234), e, do outro, há paixões - percepções ou conhecimentos -, as quais "muitas vezes não é nossa alma que as faz tais como são e porque sempre as recebe das coisas por elas representadas" (DESCARTES, I973, p. 234). 
Tendo apresentado a união nesse início, Descartes volta a falar ${ }^{4} \mathrm{da}$ distinção das substâncias, retomando o que foi dito nas Meditações, a saber, que cabe à alma o pensamento em nós existente e ao corpo, o calor e todo movimento a ele pertencente. Isto é, por não concebermos que o corpo pense, cremos pertencer à alma qualquer espécie de pensamento em nós, e, ao inverso, todo tipo de movimento e calor pertence ao corpo por ele não depender do pensamento.

O autor avança na discussão ${ }^{5}$ para a união entre corpo e alma explicando que a alma não mantém o corpo por estar unida a ele, ao contrário, este é uma máquina independente das funções do espírito. Assim, é um erro pensar que a alma domina o corpo ou que só ela é uma substância, pois o que há, na verdade, é uma íntima associação entre alma e corpo. Para explicar como isso se dá, Descartes coloca mais detalhadamente - o que nas Meditações apresentou de forma rápida - como se dá o funcionamento da glândula pineal. Diz ele que os espíritos ${ }^{6}$ animais saem do cérebro (glândula pineal) com diferentes intensidades e encontram cavidades dos músculos dispostas especificamente de tal forma, que os alongam ou distendem de maneira a produzir os movimentos.

Ora, segundo Teixeira (I990, p. 98), não é menor do ponto de vista cartesiano o abismo entre a alma e a glândula que entre a alma e o corpo como um todo. Trata-se de um mistério da natureza, de algo incompreensível ao entendimento humano, ainda que irrecusável fato da experiência. Com a afirmação de que "a alma está unida a todas as partes do corpo

\footnotetext{
4 No artigo 4, "Que o calor e o movimento dos membros procedem do corpo, e os pensamentos, da alma”.

5 Segundo Descartes (1973), artigo 5, "Que é erro acreditar que a alma dá o movimento e o calor ao corpo".

6 Descartes (1973, p. 229) identifica os "espíritos animais" como "certo ar ou vento muito sutil", e, ainda, (I973, p. 229, nota de rodapé 22), "uma chama muito viva e muito pura".
} 
conjuntamente", isto é, "a alma está verdadeiramente unida ao corpo todo" (DESCARTES, I973, p. 238), admite-se que a alma age no corpo ao mesmo tempo em que está em todas as suas partes sem perder sua essência pensante. Como sair dessa encruzilhada racionalmente? Descartes responde no artigo 34 que a sede da ação da alma sobre o corpo e do corpo sobre a alma é a glândula pineal, pois sua posição privilegiada e sua mobilidade permitem que se mova de diversas maneiras incitando de formas distintas os espíritos corporais.

Realmente é difícil conceber racionalmente como a alma inextensa está por todo o corpo extenso, mas se prova pela experiência da vida comum a harmonia do corpo, como quando se deseja mover uma parte mais distante do cérebro e cada parte funciona dentro desse mecanismo. No cotidiano, não é pelo pensamento que atestamos o movimento, ou melhor, não é pela filosofia que se aprende a interação alma-corpo, mas é a experiência que assegura os eventos da união substancial.

As paixões da alma expõem de forma mais concreta a interação da alma com o corpo por meio da glândula pineal e do funcionamento dos espíritos animais. Entretanto, ainda nesse livro não podemos dizer que Descartes tenha dado uma resposta racional ao problema do movimento corporal, pois aqui as substâncias e mesmo a união substancial são vistas por meio da metafísica. Como foi dito na explicação das cartas, a pergunta de Elisabeth remete a uma questão da vida comum e não às ideias claras e distintas. Assim, para que fosse mais fácil a Elisabeth considerar a ação da alma sobre o corpo, isto é, entender como se dá essa harmonia de que falamos acima, e, ainda, perceber que essa resposta não pode ser do tipo racional, Descartes deixou que ela atribuísse extensão à alma para entender por meio da experiência como a alma move o corpo. 


\section{CONCLUSÃO}

Estranha-se que, após Descartes ter estabelecido com tanta segurança a ordem das razões nas Meditações e de ter colocado a união substancial dentro dela, possa dizer na Correspondência que essa união não pode ser entendida pela razão. Ou melhor, nos causa um embaraço o fato de que os desdobramentos dessa união, como o movimento que a alma causa no corpo, só possam ser compreendidos fora da filosofia - na experiência. Depois de longas leituras das Meditações, ter em mãos essas cartas selecionadas traz um desconforto, pois elas apresentam uma resposta baseada na experiência para uma pergunta desejosamente racional por parte da Elisabeth.

Como mencionado, Descartes acaba explicando de uma forma "intrinsecamente inconcebível", dizendo nas Meditações que é somente ao espírito que compete conhecer as verdades, e não ao composto de espírito e corpo. Com base na leitura rápida que fizemos, pudemos ver como a questão proposta por Elisabeth na verdade não pode ser perfeitamente explicada, mas foi respondida pelo autor.

Fixado isso, pode-se justificar o fato de que foi escolhido trabalhar com as cartas a Elisabeth, pois não só apresentam dúvidas importantes ao sistema do autor, como se destaca que, dentre os escritos morais, a parte teórica é considerada principalmente a Correspondência, em especial as cartas a Elisabeth. Isso chama a atenção, pois se sabe que desde os primeiros escritos cartesianos procura-se a verdade especialmente com o propósito de fundar sobre ela uma moral racional. Desse modo, para atingir o objetivo da "árvore do saber" iniciado nas Meditações, isto é, ao buscar fundar uma nova metafísica com o intuito de formar daí uma nova física e em seguida uma moral, segundo Teixeira (I990, p. 83), o autor passa pela distinção das substâncias nas Meditações e acaba nas cartas a abordar a união. 
Descartes consegue, a partir de questões metafísicas, afastar as confusões e os erros que se encontram na física medieval, bem como constituir o fundamento de sua própria física baseada no estudo da extensão e do "movimento de suas partes", segundo Teixeira (I990, p. 84). Assim, se for lembrado que "Descartes se refere à mecânica, à medicina e à moral como os galhos da árvore da sabedoria, da qual a metafísica constitui a raiz e a física, o tronco" (TEIXEIRA, I990. p. I60), temos como resultado a necessidade de considerar a ação da alma sobre o corpo, pois para se estabelecer a física através da metafísica precisa introduzir elementos que dizem respeito não mais à substância extensa ou à substância pensante, mas à união substancial e ao homem da vida comum.

Dessa maneira, Descartes, ao buscar fundamentar a moral e a medicina, precisa considerar a existência de corpos externos, e mais, a existência do homem concreto, formado da união, incompreensível e, no entanto, evidente, de uma alma e de um corpo. A questão é que não pode mais trabalhar com o corpo como um objeto exposto diante do espírito e, portanto, inteiramente cognoscível, mas deve considerar em seus estudos o corpo vivo como um ponto de partida da ação técnica pela qual insere suas afecções e desejos no mundo. Por isso, na Meditação sexta, o pensamento, após ter sido concebido como puro espírito, descobre-se ligado de forma intima a um corpo vivido e presente. (ALQUIE, I969, p. II5).

Podem-se elencar os passos necessários para lidar com o fato de que a alma tem o poder de mover o corpo, a saber, sempre buscar estudar a interação alma-corpo pela noção primitiva de união, cujo conceito não engloba duas substâncias isoladas, mas uma união substancial; familiarizar-se com a vida prática e o senso comum para que a experiência nos mostre a melhor forma de lidar com essa questão - as ideias claras e distintas obrigam as substâncias a serem compreendidas como separadas, mas 
se essas ideias forem deixadas de lado são sentidas como união; e conhecer o corpo enquanto máquina bem como o órgão fundamental (glândula pineal) para a interação juntamente ao trabalho dos espíritos animais.

Ademais, ao propor a Elisabeth que considere a alma como extensa para entender como ela pode mover o corpo - uma vez que a explicação cabe à vida prática -, Descartes usa um elemento não racional para a explicação. Com segurança, não iremos achar nisso um erro ou uma falha no discurso. Verdadeiramente, o ponto a que a conclusão chega não foge ao projeto cartesiano, mas a aposta é que deve ser analisado justamente dentro dele. 


\section{REFERÊNCIAS}

ALQUIÉ, F. A filosofia de Descartes. Lisboa: Editorial Presença, I969.

DESCARTES, R. As paixões da alma. In: Os pensadores. Trad. Bento Prado Jr. e Jacó Guinsburg. São Paulo: Abril Cultural, 1973 .

. Carta a Elisabeth de 21 de maio de 1643; Carta a Elisabeth de 28 de junho de 1643. In:

Os pensadores. Trad. Bento Prado Jr. e Jacó Guinsburg. São Paulo: Abril Cultural, 1973.

. Tutte le lettere 1619-165o. Editor: Giuseppe Belgioso. Milão: Bompiani, 2005.

. Princípios da Filosofia. Lisboa: Ediç̧ões 70. 1997.

. Meditações metafísicas. In: Os pensadores. Trad. Bento Prado Jr. e Jacó Guinsburg. São Paulo: Abril Cultural, 1973.

. Descartes selon l'ordre des raisons. Vol. I, II. Paris: AUBIER, I99I.

LANDIM, R. F. Evidência e verdade no sistema cartesiano. São Paulo: Loyola, 1992.

. Questões disputadas de metafisica e de crítica do conhecimento. Col.

Philosophia. São Paulo: Discurso editorial, 2009.

LEWIS, R. G. La morale de Descartes. Paris: Quadrige/ Presses Universitaires de France, 1998.

TEIXEIRA, L. Ensaio sobre a moral de Descartes. São Paulo: Brasiliense, I990. 